\title{
A Novel Approach to Evaluate the Time-Variant System Reliability of Deteriorating Concrete Bridges
}

\author{
Hao Tian, ${ }^{1,2,3}$ Yuanli Chen, ${ }^{3}$ and Fangyuan $\mathrm{Li}^{4}$ \\ ${ }^{1}$ Zhejiang Scientific Research Institute of Transport, Hangzhou 310006, China \\ ${ }^{2}$ State Key Laboratory Breeding Base of Mountain Bridge and Tunnel Engineering, Chongqing Jiaotong University, \\ Chongqing 400074, China \\ ${ }^{3}$ Zhejiang Institute of Communications, Hangzhou 311112, China \\ ${ }^{4}$ Department of Bridge Engineering, College of Civil Engineering, Tongji University, Shanghai 200092, China
}

Correspondence should be addressed to Fangyuan Li; fyli@tongji.edu.cn

Received 8 October 2015; Revised 6 December 2015; Accepted 9 December 2015

Academic Editor: Egidijus R. Vaidogas

Copyright (C) 2015 Hao Tian et al. This is an open access article distributed under the Creative Commons Attribution License, which permits unrestricted use, distribution, and reproduction in any medium, provided the original work is properly cited.

Bridge time-variant system reliability is a useful measure to evaluate the lifetime performance of deteriorating bridge structures under uncertainty and is an influential performance indicator in bridge maintenance management programs. This paper proposes a computational methodology based on the Monte Carlo simulations for evaluating the time-variant system reliability of concrete bridges under environmental attacks. Methods related to the reduction of concrete sections and the variation of the load effects acting on the components are investigated using a finite element-based computational program, CBDAS (Concrete Bridge Durability Analysis System), to perform the assessment of lifetime structural performance. With regard to system reliability, a practical technique for searching the structural failure mode is also presented and a program, SRMCS (System Reliability by Monte Carlo Simulations), based on the Monte Carlo simulations is written to calculate and evaluate the structural system reliability of deteriorating concrete bridges. Finally, three numerical examples are presented to display the CBDAS and SRMCS functions.

\section{Introduction}

A large percentage of the bridges all over the world are constructed with concrete and reinforcing steel, because of their relatively low cost [1]. In recent years, however, significant distress and deterioration have been observed in many concrete bridges, mainly due to the environmental stressors such as concrete carbonation, chloride penetration, and freeze-thaw cycles. Thus, maintenance intervention to keep the structure healthy during its service life is necessary. The primary task in selecting and performing an appropriate maintenance strategy for a deteriorating concrete bridge is to evaluate and predict its lifetime structural performance [2]. To achieve this, the computational prediction should be probabilistic based, due to the inherent randomness reflected in the structural configuration, materials properties, live loads, and different environments. A comprehensive consideration of time-variant performance and uncertainty is a useful measure to assess the lifetime performance of a deteriorating bridge structure and is one of the key performance indicators in bridge maintenance management programs $[3,4]$. However, though widely accepted and used, current techniques and methods may still not be accurate enough in measuring the time-variant reliability of bridges for the following reasons: (1) the effects of the aggressive environments on the structural performance have not been precisely simulated, (2) the structural failure mode (i.e., the relationship between the overall structural failure and the individual component failure) is hard to measure; and (3) the correlation coefficients among the individual components or failure modes are difficult to determine [5-7].

Because of the shortcomings of previous techniques and methods, a finite element- and Monte Carlo simulationsbased computational methodology is proposed for evaluating the time-variant system reliability of deteriorating concrete bridges [8-10]. For time-variant performance, methods related to the reduction of concrete sections and the variation of structural load effect are discussed. For system reliability, 


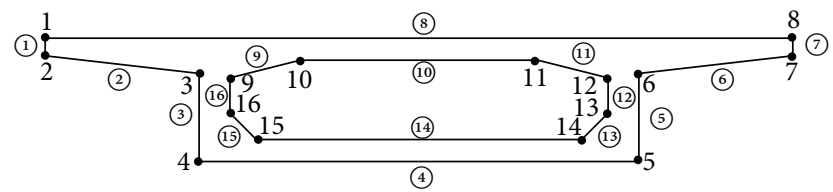

(1) Node serial number

(1) Edge serial number

(a) Simulation method

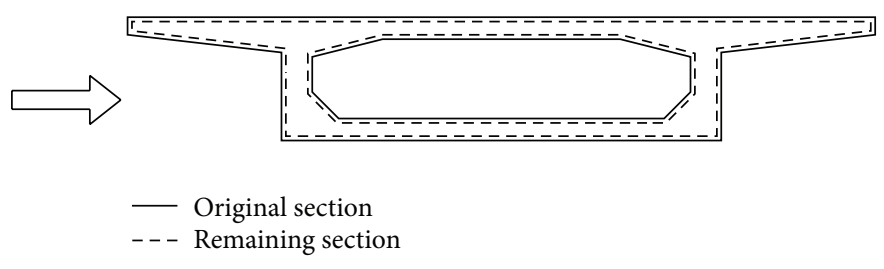

(b) Reduction process

FIgURE 1: Reduction of concrete section.

a technique for searching the structural failure mode is presented, and a Monte Carlo simulations-based program, SRMCS, is presented. Finally, three numerical examples are illustrated to display the functions of CBDAS and SRMCS and of the combination of the two programs: (1) in the first example, the time-variant performance of a reinforced concrete continuous bridge under chloride-induced corrosion is evaluated by means of CBDAS; (2) in the second example, the procedure for computing the system reliability of a two-story truss is displayed in terms of SRMCS; and (3) in the third example, the time-variant system reliability of the same model as the first example is investigated by combining CBDAS with SRMCS.

\section{Time-Variant Performance}

It is well known that the variation of structural performance with respect to the deteriorating concrete bridges may be significant during their entire service lifetime due to the environmental attacks $[9,10]$. Also, because the resistances of the individual components are time variant, it is necessary to evaluate the time-variant structural performance in an effective way by selecting an appropriate maintenance schedule.

2.1. Finite Element-Based Approach. The essential problems encountered in the assessment of lifetime performance are as follows: (1) the deterioration of the materials properties, (2) the reduction of sectional areas, and (3) the variation of the overall structural performance induced by the first two problems. Furthermore, the last two problems can be divided into the reductions of reinforcing steel and concrete sections, the deterioration of resistances of the individual components, and the variation of load effects acting on these components. The two main problems to be investigated in this paper are the reduction of concrete sections due to environmental attacks and the variation of the load effects acting on the individual components.

2.1.1. Reduction of Concrete Sections. When considering the reduction of a concrete section, it is necessary to simulate the accurate shape of the section, as it is one of the critical factors related to measuring the actual reduction process. One way to accurately do this is to simulate the section by using the concrete edge as the basic unit because the reduced depths of the concrete edges in the same section are likely to be not identical due to the different values of the environmental parameters and other design variables among the concrete edges. It can be seen from Figure 1(a) that the number of the edges is equal to that of the nodes. Thus, the edge information can be obtained from the coordinates of the control nodes. The cross-sectional geometrical properties can be thus calculated associated with the node coordinates and the Triangle Partitioning Method $[11,12]$ and by using the edge as basic unit, the reduction process of concrete section can be described as the movement of the concrete edges. The specific steps are as follows: (1) the corrosion rate of the reinforcing steel related to each concrete edge is calculated by means of the corrosion numerical model, (2) the reduced depths of the two adjacent concrete edges are obtained in association with the corrosion rates of the reinforcing steels on the two edges, (3) each edge moves a distance equal to the respective reduced depth along its normal direction and a group of new control nodes are obtained as the intersections of the moved concrete edges, and (4) the remaining concrete section can be generated with the same method as the original one. The reduction process is shown in Figure 1(b), where the figure surrounded by solid lines is the original concrete section and the one encircled by dashed lines is the remaining section.

2.1.2. Variation of Load Effect. The key problems derived from the variation of the load effects acting on the individual components are the loss of dead weight and internal force redistribution due to the reduced concrete and steel bar sections. In the case of a concrete section, the computation of the lost dead weight is similar to assessment by conventional analyses. Only two problems are required to be modified: (1) the area of the original concrete section should be replaced by the reduced concrete section when forming the load vector caused by the lost dead weight and (2) the load induced by the lost dead weight should be applied on the deteriorating structure in the opposite direction of the original dead weight. In the reinforcing steel and prestressing steel sections, corrosion cannot lead to the loss of dead weight because they are wrapped in the concrete section and the dead weight of the rust is consistently acting on the structure over its life cycle. The internal forces acting on the reduced concrete section, reinforcing the steel section and its prestressing section, need to be redistributed on the deteriorating structure. The internal force redistribution of reduced concrete section is shown in Figure 2, where $I_{c, c}, I_{c}$, and $I_{c, h}$ are the geometric centers of the reduced, original, and remaining concrete sections, respectively. $N_{c, c}$ and $N_{c, h}$ are the internal forces acting on the reduced and remaining 


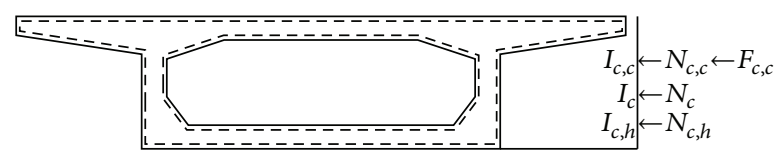

FIGURE 2: Redistribution of the internal forces.

concrete sections, respectively, which are decomposed from $N_{c}$, the internal force acting on the original concrete section, based on the cross-sectional geometric properties of the reduced, original, and remaining concrete sections. Thus, load $F_{c, c}$ caused by the reduction of the concrete section is identical to the internal force $N_{c, c}$. In a similar way, loads $F_{s, c}$ and $F_{p, c}$ induced by the reduction of reinforcing steel and prestressing steel sections are obtained. Finally, load $F_{c}$ due to the internal force redistribution of the reduced sections is composed of $F_{c, c}, F_{s, c}$, and $F_{p, c}$.

2.2. Computational Program: CBDAS. The analysis procedure of the structural time-variant performance is displayed in Figure 3. A finite element-based approach to evaluate the time-variant performance of deteriorating concrete bridges is set up based on the solutions of the abovementioned essential problems. Accordingly, a program named CBDAS (i.e., Concrete Bridge Durability Analysis System) [13] has been developed to perform this approach by using FORTRAN. The program has two major functions. The first is to simulate the physical events from the initiation of construction to its completion, which can be characterized as the construction process analysis, and the second is to evaluate the timevariant structural performance from structural completion to the occurrence of the limit state or the end of service life, which can be defined as the degradation process analysis. Figure 3 displays the flow chart of CBDAS.

\section{System Reliability}

Structural system reliability defines safety as the condition in which a system failure will not occur from a probabilistic standpoint. To accurately evaluate system reliability, it is necessary to follow an approach called "StructureComponent-Structure." This approach can be divided into two steps: (1) deduction from the overall structure to individual components and (2) induction from the individual components to overall structure [14]. In the first step, the resistances of individual components and the load effects acting on these components are calculated based on the structural configuration, loads, and construction method. The limit state functions of these individual components or failure modes are formulated by equations relating the load effects to the relative resistances and the components reliabilities are evaluated accordingly. In the second step, the structural failure mode is required to be searched according to the relationship between the overall structure failure and the individual component failure. Finally, the system reliability can be assessed in association with the components' reliabilities and the structural failure mode. The schematic for calculating the system reliability is shown in Figure 4.
In the following part of this section, the conventional methods for calculating the structural system reliability are briefly reviewed. Afterwards, an approach for evaluation of the system reliability associated with Monte Carlo simulations and a practical structural failure mode searching technique is proposed.

3.1. The Conventional Methods. The commonly used methods for calculating the structural system reliability are (1) the incremental method and (2) the series-parallel modeling method.

3.1.1. The Incremental Method. The incremental method [15] is used to search the structural failure mode and thus formulate the limit state function of the overall structure. The objective of this method is to find out an expression for the system resistance in terms of the component resistances. The method identifies a system failure mode by following a load path from initial component failure to final system collapse and leads to a linear system failure expression such as $[2,16]$

$$
g_{j}=\sum C_{j k} R_{k}-S_{j},
$$

where the failure function $g_{j}<0$ means that the $j$ th failure has occurred. $C_{j k}$ is the coefficient representing the participation of the $k$ th component in the $j$ th failure mode; $R_{k}$ is the resistance of the $k$ th component; and $S_{j}$ is the load term in the $j$ th failure mode. The system reliability $R_{s}$ is expressed as $[2,16,17]$

$$
R_{s}=\text { Probability }\left[\text { All } g_{j}>0\right] \text {. }
$$

It is clear that (1) is a system limit state function, based on which the system reliability can be calculated directly by using the integration method or Monte Carlo simulations. In this method, the deduction from structure to components and the induction from components to structure are both implied in the process of searching the load path from initial component failure to final system collapse. This method is applicable to straightforwardly estimating the probability of system failure related to some simple structures. The drawback of the method, however, is the difficulty in finding all the system failure modes with respect to the complex structures. Therefore, it is hard to be applied in evaluating system reliabilities of complex structures.

3.1.2. The Series-Parallel Modelling Method. Another conventional method is the series-parallel modeling method [17]. The goal of this method is to simplify the overall structure to a series-parallel model. The system reliability is a function of the series-parallel model, the individual reliabilities of all possible failure modes for each of the components in the model, and the correlations among the failure modes $[10,16$, 18]. A series system is sometimes referred to as the weakest link system, since the failure of the system corresponds to the failure of the weakest component in the system [17]. The probability of system failure of a series system can be expressed as

$$
P_{s}=\text { Probability }\left[\text { Any } g_{i}<0\right] \text {, }
$$



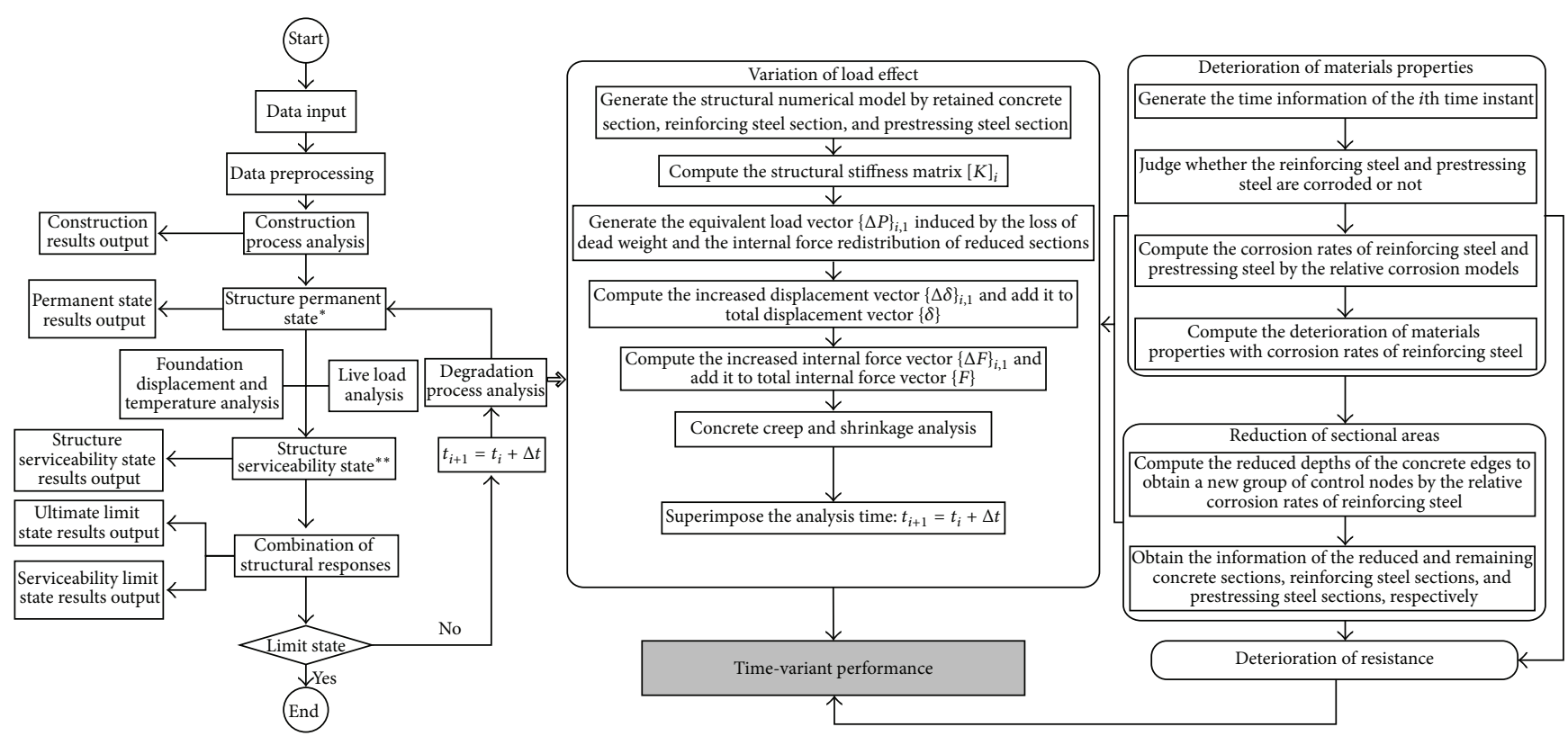

FIgURE 3: The flow chart of CBDAS for the analysis procedure of the time-variant performance. $*$ : structure permanent state is the structural response with dead loads, such as structural weight, construction process, deck pavement, lost dead weight, and internal force redistribution. **: structure serviceability state is the structural response with variable loads, such as vehicle, people, and temperature.

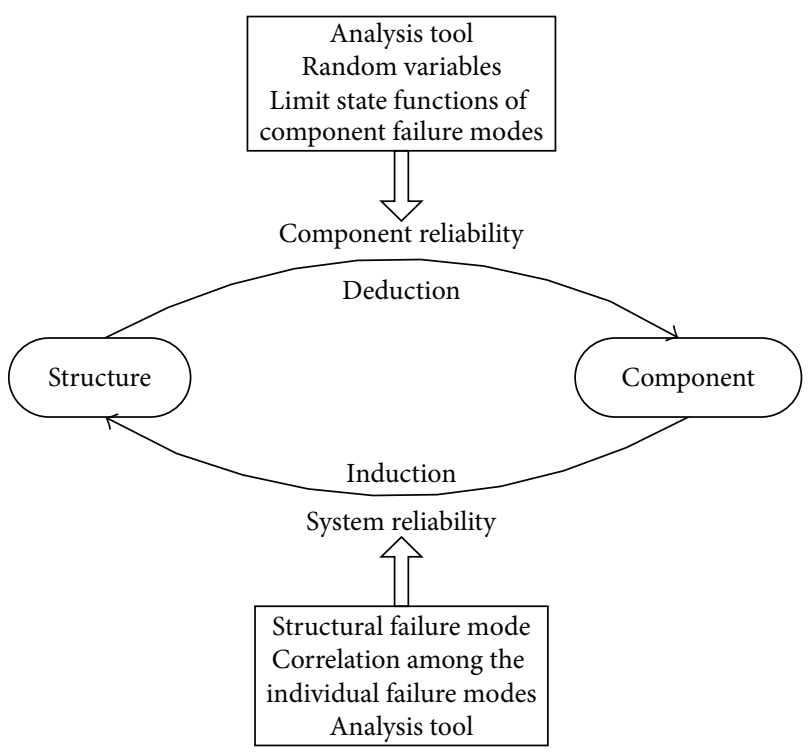

FIGURE 4: Schematic for calculating the system reliability.

where $P_{s}$ is the probability of system failure and $g_{i}$ is the limit state function of the $i$ th component failure mode. A parallel system is in a state of failure when all of its elements fail [17] and its probability of system failure should be

$$
P_{s}=\text { Probability }\left[\text { All } g_{i}<0\right] \text {. }
$$

Actually, most of the structures should be considered as the combination of series and parallel systems. Such systems are referred to as hybrid or combined systems. This method provides a rather comprehensive insight into the relationship between the overall structure and the individual components and, as a consequence, induction from the components to the structure is effectively solved. Furthermore, deduction from structure to components can be performed by using finite element analysis with respect to the complex structures or calibrated limit state functions with respect to the simple structures. The obstacle of this method, however, is in the determination of the correlations among the individual components failure modes. For this reason, the assumed values of the correlation coefficients are commonly used in previous studies and thus the accuracy of the results cannot be guaranteed.

3.2. Monte Carlo Simulations-Based Method. To overcome the deficiencies involved in the conventional methods, a Monte Carlo simulations-based approach is presented herein, which can be divided into two sections: (1) a component reliability calculating method and (2) a structural failure mode searching technique. The first section presents the analysis related to deduction from the structure to components associated with the geometry and layout of the structure, its external loads, along with a construction method. The objective of the second section is to determine the relationship between individual component failure and overall structural failure.

3.2.1. Component Reliability. The two essential ingredients for calculating component reliability are the limit state function and the analysis method. A limit state function is related to the difference between the resistance and load effect [1820]. Based on finite element analysis, the state function of component failure mode $i$ can be formulated by means of 
the physical quantity of interest (e.g., flexural moment and shear force) as

$$
g_{i}\left(\mathbf{q}_{i}\right)=R_{i}-S_{i},
$$

where $\mathbf{q}_{i}$ represents a group of variables with respect to the physical quantity of component failure mode $I$ and $R_{i}$ and $S_{i}$ are the resistance and load effect in component failure mode $i$. Hence, the effect of the structural configuration, construction method, and external loads on $R_{i}$ and $S_{i}$ can be comprehensively taken into account by using the proposed approach. The finite element-based method proposed in the previous section is utilized to evaluate $R_{i}$ and $S_{i}$, and several analytical methods can be used to calculate the component reliability, such as the first-order (FORM) or second-order (SORM) moment methods. First-order [21] or, more accurately, second-order [22] method is applicable to accounting for the correlations among the resistances and load effects reflected in the component limit state functions and can estimate the component reliabilities efficiently. Alternatively, Monte Carlo simulations can be performed to directly evaluate the probability of individual failure more accurately. Monte Carlo simulations are selected herein to evaluate the component reliability, in order to better combine with the searching technique of the structural failure mode introduced in the latter section.

3.2.2. Structural Failure Mode. To determine the structural failure mode, the most formidable task is to determine the relationship between overall structure failure and individual component failure to determine when the failure of an individual component has occurred and whether the overall structure is still safe or not $[23,24]$. In this study, a practical technique for searching the structural failure mode proposed is mainly based on the degree of static indeterminacy of the overall structure [25]. The proposed technique can be described as the following steps:

(1) Search out the subsets of component failure modes according to the geometry and layout of the overall structure. Each subset, composed of several component failure modes, represents one of the local behaviors or the overall performance of the structure. The reasons for defining these subsets as such are as follows: (1) local failure can induce the overall structure collapse and (2) the number of component failure modes in a subset triggering the local failure may be less than the one in the subset leading to the system failure. At least one subset should be taken into account, in which all the component failure modes of the structure are included and, furthermore, the same component failure mode can appear in the different subsets simultaneously.

(2) Decide the minimum degree of static indeterminacy of the structure based on the structural original degree of static indeterminacy and the expert advice. The minimum degree should be between 0 and the original degree of static indeterminacy.

(3) Determine the minimum number of the occurring component failures that can trigger the local failure or the system failure in each subset. The minimum number related to the subset, where all the component failure modes are included, should be equal to

$$
N_{s}=D_{o}-D_{a}+1
$$

where $N_{s}$ is the minimum number of the occurring component failures triggering the system failure, $D_{o}$ is the original degree of static indeterminacy of the structure, and $D_{a}$ is the designated minimum degree of static indeterminacy of the structure. In the case of other subsets, the smallest numbers can be determined in terms of the local configuration and the expert advice, and meanwhile, they should be less than $N_{s}$.

Finally, it is clear that the structural failure mode should be composed of the subsets related to the component failure modes, the designated minimum degree of static indeterminacy of the structure, and the minimum number of occurring component failures triggering the local failure or the system failure in each of the subsets. In the $i$ th deterministic analysis, if the number of the occurring component failures in any of the subsets is equal to or even more than the designated minimum number, the overall structure is failure.

Two examples are illustrated to display the proposed structural failure mode searching technique. The first example is a one-story truss shown in Figure 5(a). The truss is composed of five bars (components) and the original degree of static indeterminacy of the structure is 1 . The tensile or compressive failure of each bar is considered and thus the total component failure modes are 5. Based on the proposed technique, two different structural failure modes can be searched out, in which only one subset is included, respectively. The subset is composed of all the component failure modes in the structure. The difference of the two structural failure modes is the designated minimum degree of static indeterminacy of the structure. If the minimum degree is defined as 0 , the minimum number of the occurring component failures in the subset should be 2 . If the structure is required to be conservatively constructed according to the expert advice, however, the minimum degree is assumed to be 1 . Therefore, the minimum number of the occurring component failures is 1 . In this case, the overall structure is similar to a series system, since the occurrence of any component failure can trigger the system failure.

The second example shown in Figure 5(b) is a two-story truss with 10 bars (components). Based on the structural mechanics analysis, the original degree of static indeterminacy is investigated to be 2 , and the proposed technique is used to search the structural failure modes. The overall structure can be divided into two one-story trusses including bars $1-5$ and bars 6-10, respectively. Thus, three subsets should be considered and the component failure modes included in these subsets are tensile (compressive) failures of bars $1-5$, bars $6-10$, and bars $1-10$, respectively. In this example, three structural failure modes can be sought out, and in the first failure mode, the minimum degree of static 
TABLE 1: Critical parameters involved in the structural failure modes.

\begin{tabular}{|c|c|c|c|c|c|}
\hline $\begin{array}{l}\text { Parameters } \\
\text { Examples }\end{array}$ & $\begin{array}{c}\text { Structural } \\
\text { failure mode }\end{array}$ & $\begin{array}{l}\text { Minimum degree of } \\
\text { static indeterminacy }\end{array}$ & Subset & $\begin{array}{l}\text { Minimum number of } \\
\text { the occurring CFMs* }\end{array}$ & Including CFMs \\
\hline \multirow{2}{*}{ One-story truss } & 1 & 0 & 1 & 2 & $1-5$ \\
\hline & 2 & 1 & 1 & 1 & $1-5$ \\
\hline \multirow{5}{*}{ Two-story truss } & & & 1 & 2 & $1-5$ \\
\hline & 1 & 0 & 2 & 2 & $6-10$ \\
\hline & & & 3 & 3 & $1-10$ \\
\hline & 2 & 1 & 1 & 2 & $1-10$ \\
\hline & 3 & 2 & 1 & 1 & $1-10$ \\
\hline
\end{tabular}

${ }^{*}$ CFMs: component failure modes.

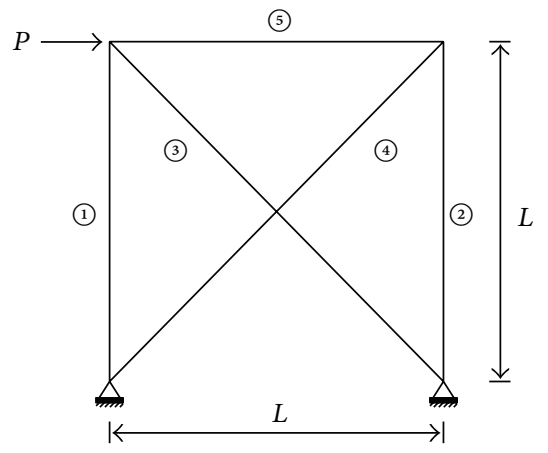

(a) The geometry of a one-story truss

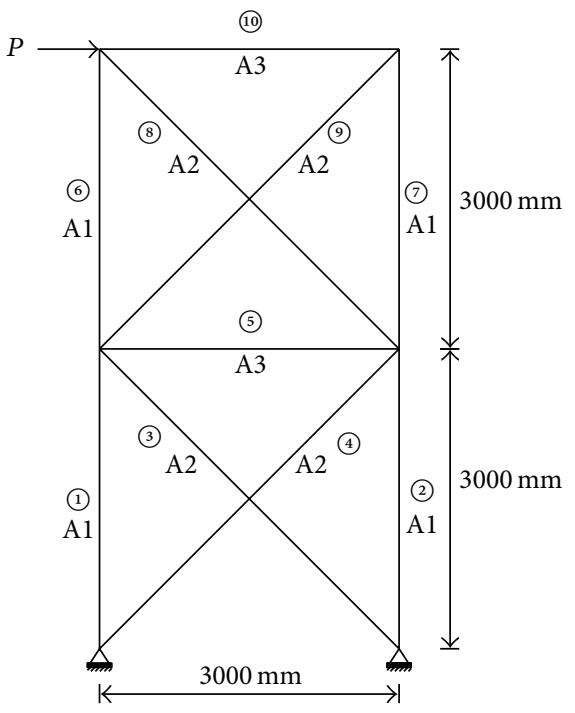

(b) The geometry of a two-story truss

Figure 5: The geometry of example truss.

indeterminacy is defined as 0 (i.e., the static determinacy is allowable). Consequently, minimum numbers of the occurring component failures in the subsets are 2, 2, and 3, respectively. In the case of the second failure mode, the minimum degree of static indeterminacy is assumed as 1 with conservative consideration derived from the expert advice, and the minimum numbers of the occurring component failures in the three subsets are all identical to 2 . In this case, since the third subset includes all the component failure modes, the other two subsets are included in this subset and the number of the subsets is reduced to 1 . As for the third failure mode, if more conservative consideration is required, the minimum degree of static indeterminacy is assumed to be 2 . Similar to the second structural failure mode, only the subset containing all the component failure modes is necessary to be investigated and its minimum number of the occurring component failures should be 1 . The values of critical parameters encountered in the structural failure modes relating to the abovementioned two examples are summarized in Table 1.

A Monte Carlo simulations-based method for evaluating the system reliability is set up based on the proposed structural failure mode searching technique. Accordingly, a program named SRMCS (System Reliability by Monte Carlo Simulations) [13] and written in MATLAB has been developed to perform this approach. Figure 6 shows the schematic of the proposed method for calculating the system reliability.

\section{Numerical Examples}

Three numerical examples are illustrated to display the functions of CBDAS, SRMCS, and the combination of the two programs. In the first example, the time-variant performance of a reinforced concrete continuous bridge under chlorideinduced corrosion is evaluated by means of CBDAS; in the second example, the procedure to calculate the system reliability of a two-story truss is displayed by using SRMCS; and in the last example, the time-variant system reliability related to the same model as the first example is calculated by combination of CBDAS and SRMCS.

4.1. Example 1. In the first example, the lifetime performance of a reinforced concrete continuous bridge shown in Figure 7 


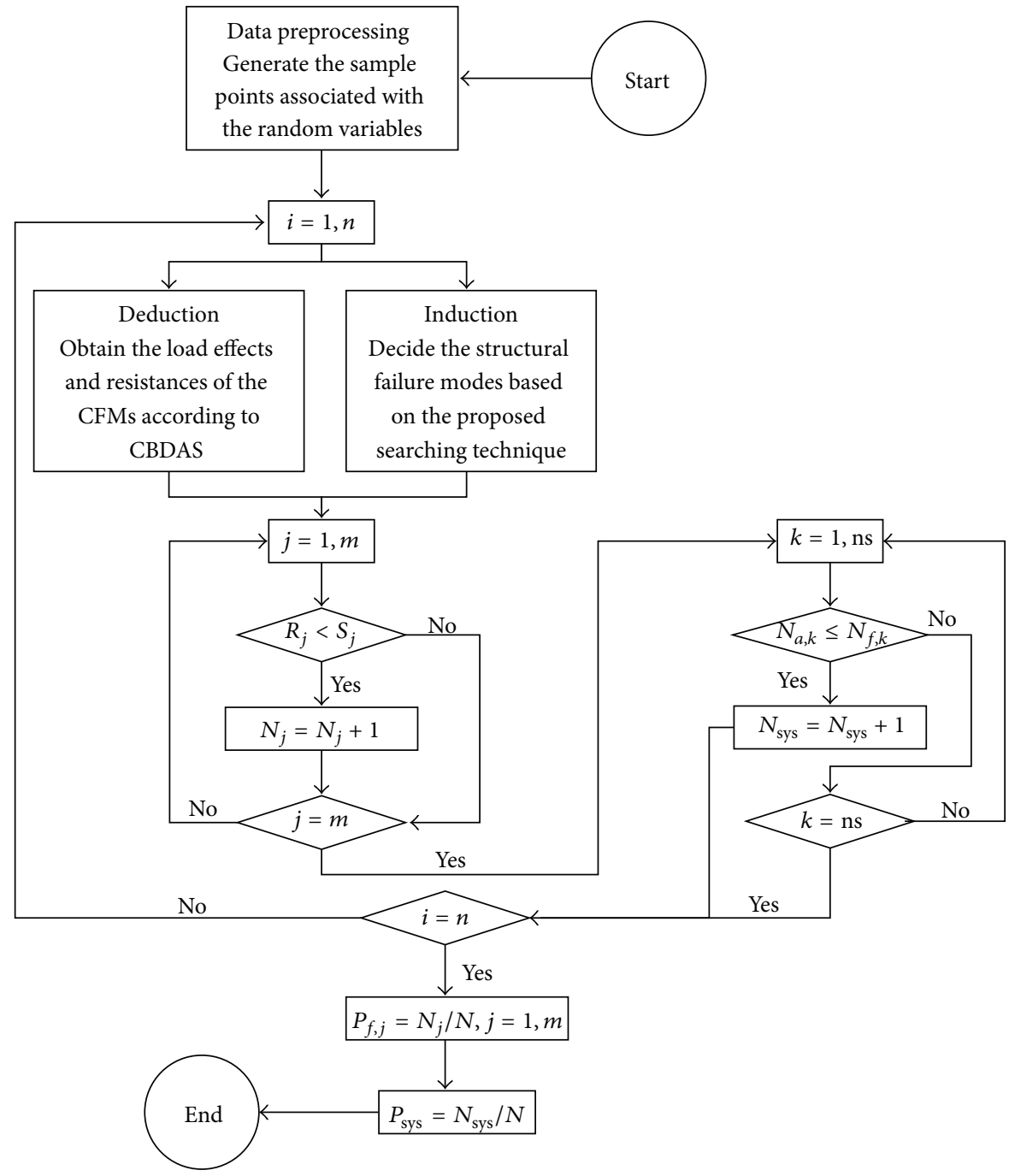

$n$ : number of sample points

CFMs: component failure modes

$m$ : number of CFMs

ns: number of subsets, each of which includes some CFMs

$N_{a, k}$ : minimum number of the occurring CFMs in subset $k$ triggering system failure
$N_{f, k}$ : number of the occurring CFMs in subset $k$

$P_{f, j}:$ the probability failure of component failure mode $j$

$P_{\text {sys }}$ : the probability failure of system

FIgURE 6: Schematic of the proposed method for calculating the system reliability.

is discussed. This bridge, located in Shanghai, China, is a $3 \times$ $22 \mathrm{~m}$ three-span reinforced concrete continuous girder bridge with a single-box section. In this study, since the model bridge is near East China Sea and the concentration of chloride ion in the atmosphere may be relatively high, chloride-induced corrosion is taken into account. The values of the major parameters are listed in Table 2 . It should be noted that the chloride ion concentrations at the different surfaces of the concrete section may be not identical. For this reason, the values of the chloride ion concentrations at different concrete edges are determined as shown in Table 3. The prescribed service life is defined as 100 years.
Figure 8 shows three critical times in the degradation process related to all the edges involved in the concrete section at the midspan center in the model bridge. The differences of the same critical time among the concrete edges are evident since the values of the design parameters among the concrete edges are not identical. The shortest critical times appear on edge 7, with the values of 19, 22, and 24 years, because the minimum concrete cover depth, the highest concentration of chloride ion, and the largest diameter of reinforcing steel happen to appear in this edge. On the contrary, the critical times of edge 18 are the longest among all the edges in the concrete section. The corrosion initiation 


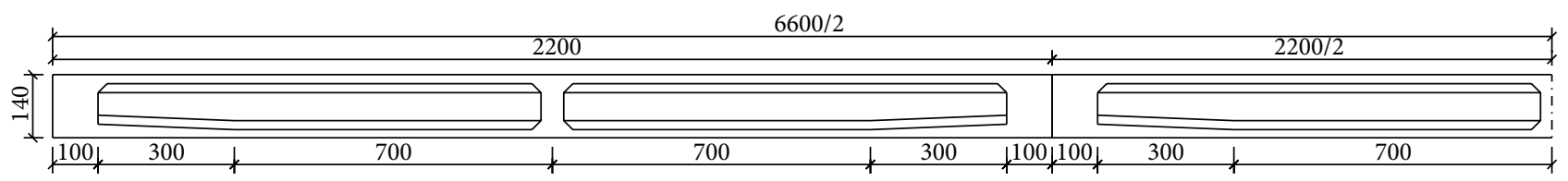

(a) Half elevation of continuous box girder/cm

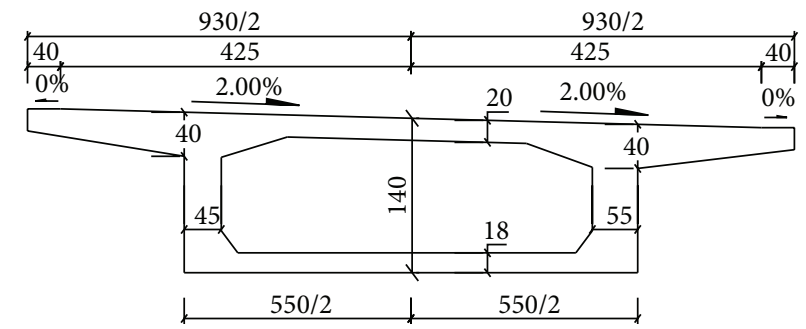

(b) Box girder section $/ \mathrm{cm}$

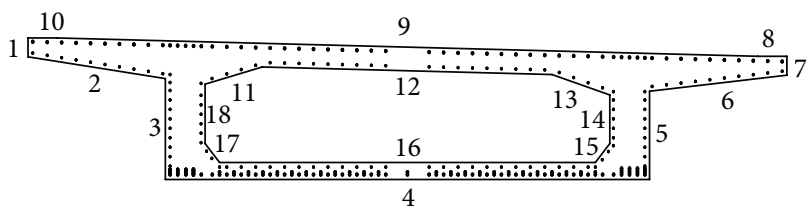

(1) Edge serial number

(c) Layout of reinforcement

FIgURE 7: Profile of reinforced concrete continuous bridge.

TABLE 2: Values of the major parameters.

\begin{tabular}{lcc}
\hline Variable & Value & Variable description \\
\hline$E_{c}$ & $34,500 \mathrm{MPa}$ & Concrete elastic modulus \\
$f_{c}$ & $32.4 \mathrm{MPa}$ & Concrete compressive strength \\
$E_{s}$ & $200,000 \mathrm{MPa}$ & Reinforcing steel elastic modulus \\
$f_{s}$ & $335 \mathrm{MPa}$ & Reinforcing steel tensile strength \\
$C$ & $C_{\text {nom }}{ }^{\mathrm{a}}$ & Concrete cover thickness \\
$d_{s}$ & $d_{s, \text { nom }}{ }^{3}$ & Reinforcing steel diameter \\
$\gamma_{c}$ & $25 \mathrm{kN} / \mathrm{m}^{3}$ & In situ concrete unit weight \\
$\gamma_{s}$ & $78.5 \mathrm{kN} / \mathrm{m}^{3}$ & Reinforcing steel unit weight \\
$\gamma_{a}$ & $23 \mathrm{kN} / \mathrm{m}^{3}$ & Deck paving unit weight \\
$Q$ & $10.5 \mathrm{kN}$ & Uniform live load \\
$P$ & $250 \mathrm{kN}$ & Concentrated live load \\
$M_{s}$ & $6.9 \mathrm{~kg} / \mathrm{m}^{3}$ & Surface chloride concentration \\
$M_{\text {cr }}$ & $1.5 \mathrm{~kg} / \mathrm{m}^{3}$ & Critical chloride concentration \\
$D_{c}$ & $22.5 \mathrm{~mm} /$ year & Diffusion coefficient \\
\hline${ }^{\mathrm{a}} C_{\text {nom }}$ is the cover thickness of some concrete edge in the section. \\
${ }^{\mathrm{b}} d_{s, \text { nom }}$ is the reinforcing steel diameter of some concrete edge in the section.
\end{tabular}

TABLE 3: Values of chloride ion concentrations at different concrete edges.

\begin{tabular}{|c|c|c|}
\hline Concrete edge & $\begin{array}{l}\text { Environmental } \\
\text { condition }\end{array}$ & Value \\
\hline $5,6,7$ & Face to the sea & $100 \%$ of the value in Table 2 \\
\hline $1,2,3$ & Back to the sea & $70 \%$ of the value in Table 2 \\
\hline $4,8,9,10$ & $\begin{array}{l}\text { Between the first two } \\
\text { conditions }\end{array}$ & $85 \%$ of the value in Table 2 \\
\hline $11-18$ & Interior edges & $\begin{array}{c}\text { Half of the value of relative } \\
\text { exterior edges }\end{array}$ \\
\hline
\end{tabular}

times of 10 concrete edges from the total eighteen concrete edges are less than 100 years (i.e., the prescribed service life), and as a consequence, the corrosion of reinforcing steel and concrete cracking have only occurred in the 10 edges. Compared with the concrete edges in exterior surface, the

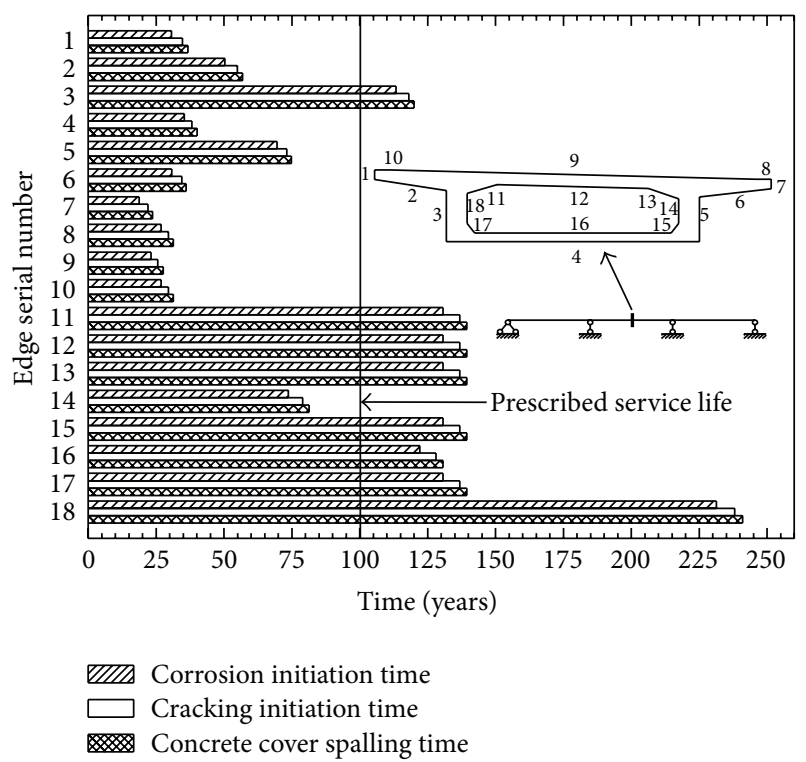

FIGURE 8: Critical times in the degradation process.

edges of the interior surface have relatively long critical times due to the low concentrations of chloride ion. The corrosion initiation times of all the interior concrete edges are longer than 100 years except edge 14, where the cover thickness is comparatively thin. Since the critical times related to the concrete edges may be significantly different as a result of the various values of the environmental and other design parameters, the conclusion can be drawn that it is necessary to form the concrete section by using its edges as the basic unit based on the above results, when the lifetime structural performance is investigated.

Figure 9 displays the time-variant area loss rates of reinforcing steel and concrete sections at the midspan center in the model bridge. It is clear that the area loss of reinforcing steel section initiates at about 19 years, which corresponds to the results shown in Figure 8 where the earliest corrosion initiation time is also 19 years. The corrosion rate gradually 


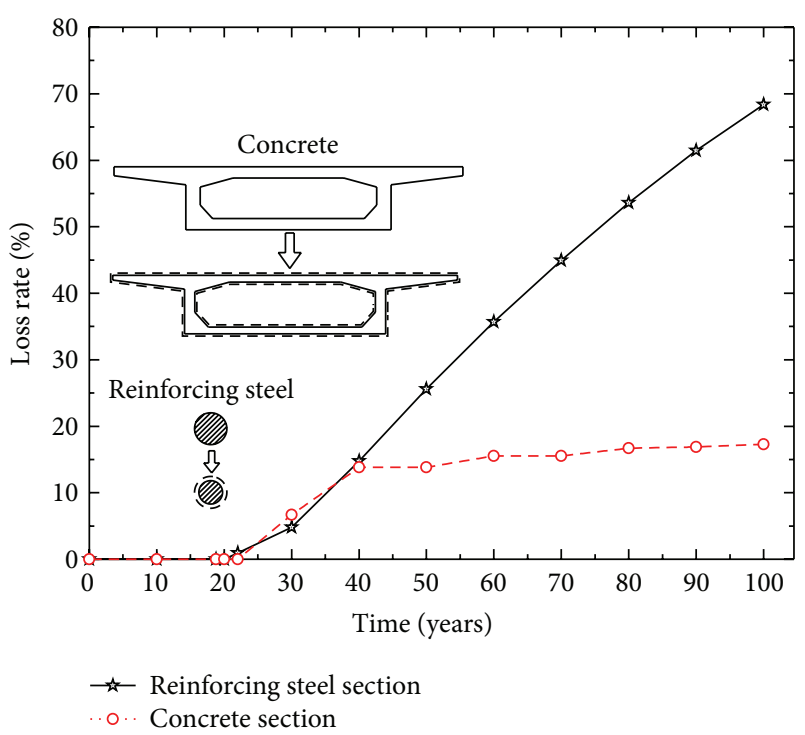

FIgURE 9: Time-variant area loss rates of reinforcing steel and concrete sections.

increases from 20 years to 40 years, since the concrete at seven edges begins to crack during this period accelerating the corrosion of reinforcing steels wrapped in these concrete edges. At the end of service life, the area loss rate of reinforcing steels wrapped in the entire concrete section reaches about $70 \%$. In the case of concrete, it is clear from Figure 9 that its section begins to reduce at about 22 years. Note that the increase in area loss rate of the concrete section is not significant after 40 years. This is because (1) the entire concrete covers at seven edges are all spalling during the first 40 years and the concrete is assumed not to continue cracking in these edges and (2) the concrete at only three edges cracks and leads to the reduction of concretion section after 40 years. Finally, the area loss rate of the concrete section is about $17.3 \%$ at 100 years.

To determine the effect of environmental attack on the lifetime structural performance, two time-variant performance cases with and without the environmental effect are now considered the structural vertical displacement. Figure 10 displays the variations of the vertical displacements at two critical locations (i.e., the side-span and middle-span centers). Note that the displacement along the direction of $y$-axis in the global coordinate system is assumed as positive. In the first 10 years after structural completion, the variations of the vertical displacements are significant due to the concrete creep and shrinkage. When the environmental effect is considered, the time-variant vertical displacements after the first 10 years can be described as follows: (1) from 10 years to 20 years, the variations of vertical displacements are not evident, since the effect of concrete creep and shrinkage is gradually weak and the corrosion initiation times related to most of the reinforcing steels are longer than 20 years; (2) from 20 years to 100 years, the variations of vertical displacements are gradually significant again due to the reductions of reinforcing steel and concrete sections as a result of the reinforcing steel corrosion and concrete cracking.

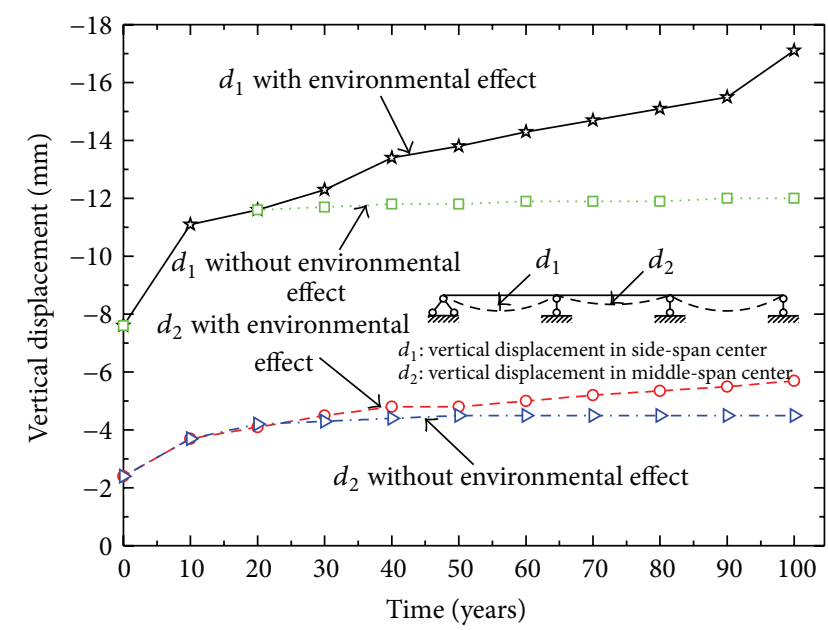

FIGURE 10: Variations of vertical displacements at critical locations.

The degree of variation caused by the environmental effect is similar to the one induced by concrete creep and shrinkage. When the environmental effect is not considered, the vertical displacements at the two critical locations are nearly invariant after 10 years.

The flexural moment and the ultimate limit stage are now discussed where the variations of the flexural moments at two critical locations (i.e., the side-span center and the middle-pier top) are shown in Figure 11. The flexural moment leading to tensile stress at the bottom of the concrete section is assumed to be positive and the time-variant flexural moment throughout the service life can be described as follows. In the first 10 years after structural completion, the evident variations of the flexural moments are the result of concrete creep and shrinkage. If the environmental effect is considered, the variations of the flexural moments during the subsequent 10 years and from 20 years to 100 years are apparent and significant, due to the same reasons as that of the vertical displacement. When the environmental effect is not considered, the variations of the flexural moments at the two critical locations are insignificant after 10 years. It should be noticed, from this figure, that the variations of the flexural moments at the two critical locations with the environmental effect are not monotonic during service life. This is because of (1) the time-variant location of the neutral axis of concrete section due to the reduction of the section; (2) the loss of dead weight induced by the reduction of concrete section; and (3) the redistribution of the internal force caused by the reductions of reinforcing steel and concrete sections. For these results, the flexural moment may increase or decrease over the life cycle of a structure.

4.2. Example 2. In the third example, the same model as the first example shown in Figure 7 is used to illustrate the computation of time-variant system reliability associated with the proposed methods for calculating the time-variant performance and system reliability. The distribution types and associated statistical descriptors of the random variables involved in the structural configuration, materials properties, live loads, and environment are summarized in Table 4, 


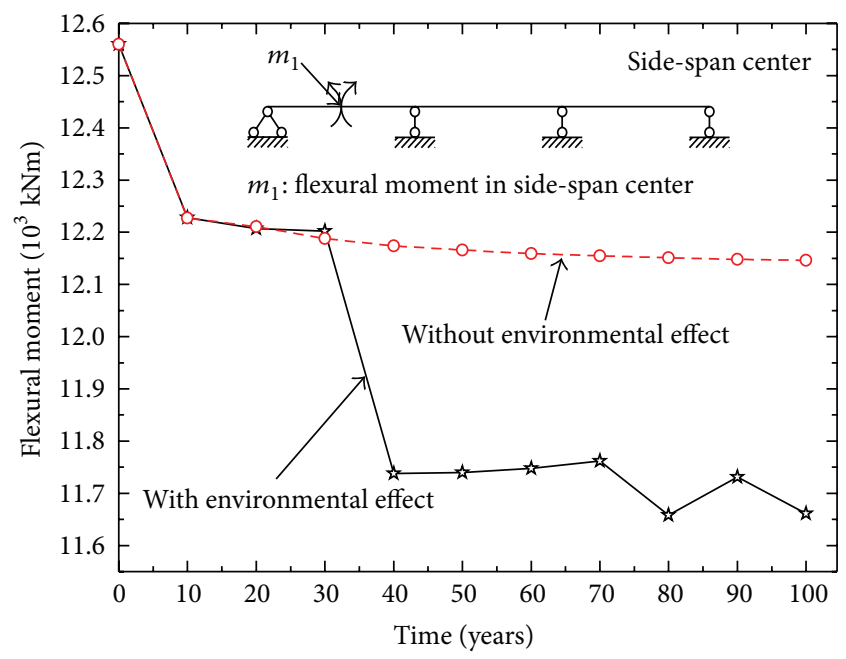

(a) Side-span center

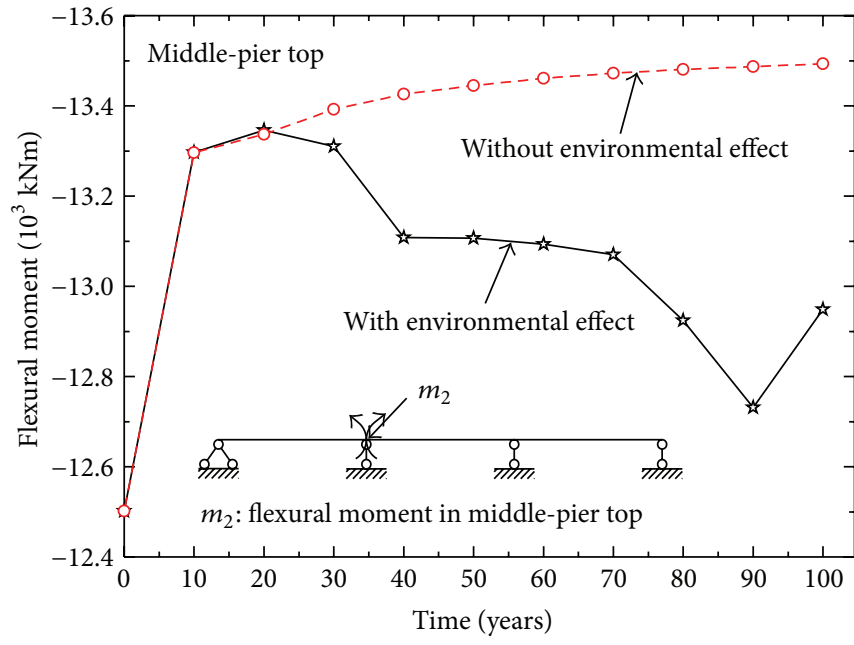

(b) Middle-pier top

FIGURE 11: Variations of flexural moments at critical locations.

TABLE 4: Statistical parameters of random variables.

\begin{tabular}{|c|c|c|c|c|}
\hline Variable & Nominal & Mean & $\mathrm{COV}^{\mathrm{a}}$ & Distribution type \\
\hline$\overline{E_{c}}$ & $34,500 \mathrm{MPa}$ & $34,500 \mathrm{MPa}$ & 0.10 & Normal $^{\mathrm{b}}$ \\
\hline$f_{c}$ & $32.4 \mathrm{MPa}$ & $40.5 \mathrm{MPa}$ & 0.12 & Normal $^{\mathrm{b}}$ \\
\hline$E_{s}$ & $200,000 \mathrm{MPa}$ & $200,000 \mathrm{MPa}$ & 0.06 & Normal $^{\mathrm{b}}$ \\
\hline$f_{s}$ & $335 \mathrm{MPa}$ & $375 \mathrm{MPa}$ & 0.065 & Normal $^{\mathrm{b}}$ \\
\hline C & $C_{\text {nom }}$ & $1.02 C_{\mathrm{nom}}$ & 0.05 & Normal $^{\mathrm{b}}$ \\
\hline$d_{s}$ & $d_{s, \mathrm{nom}}$ & $1.0 d_{s, \text { nom }}$ & 0.02 & Normal $^{\mathrm{b}}$ \\
\hline$\gamma_{c}$ & $25 \mathrm{kN} / \mathrm{m}^{3}$ & $26 \mathrm{kN} / \mathrm{m}^{3}$ & 0.06 & Normal $^{\mathrm{b}}$ \\
\hline$\gamma_{s}$ & $78.5 \mathrm{kN} / \mathrm{m}^{3}$ & $80.1 \mathrm{kN} / \mathrm{m}^{3}$ & 0.05 & Normal $^{\mathrm{b}}$ \\
\hline$\gamma_{a}$ & $23 \mathrm{kN} / \mathrm{m}^{3}$ & $23 \mathrm{kN} / \mathrm{m}^{3}$ & 0.04 & Normal $^{\mathrm{b}}$ \\
\hline$Q$ & $10.5 \mathrm{kN}$ & $9.03 \mathrm{kN}$ & 0.08 & Extreme value type I \\
\hline$P$ & $250 \mathrm{kN}$ & $215 \mathrm{kN}$ & 0.08 & Extreme value type I \\
\hline$M_{s}$ & $6.9 \mathrm{~kg} / \mathrm{m}^{3}$ & $6.9 \mathrm{~kg} / \mathrm{m}^{3}$ & 0.1 & Normal $^{\mathrm{b}}$ \\
\hline$M_{\mathrm{cr}}$ & $1.5 \mathrm{~kg} / \mathrm{m}^{3}$ & $1.5 \mathrm{~kg} / \mathrm{m}^{3}$ & 0.15 & Normal $^{\mathrm{b}}$ \\
\hline$D_{c}$ & $22.5 \mathrm{~mm}^{2} /$ year & $22.5 \mathrm{~mm}^{2} /$ year & 0.45 & Lognormal \\
\hline
\end{tabular}

${ }^{\mathrm{a}} \mathrm{COV}$ is the coefficient of variation.

${ }^{\mathrm{b}}$ Truncated distributions with nonnegative outcomes are adopted in the simulation process.

according to the structural drawing and relative literatures [26]. The prescribed service life and the unit calculating time are assumed as 100 years and 10 years, respectively. The same as the second example, the number of samples in Monte Carlo simulations is defined as 200,000 .

Based on the structural decomposition technique presented in [13], the three-span reinforced concrete bridge is divided into 21 components, with seven components in each span. Ultimate limit state is only discussed here, since the structural resistance is more likely to deteriorate significantly due to the area loss of reinforcing steel section over the life cycle of a structure. When two component failure modes, flexure failure and shear failure, are taken into account, the number of the component failure modes is 42 for overall structure and 14 for each span as shown in Figure 12, and the key parameters of the structural failure mode are summarized in Table 5. Three structural failure modes can be sought out

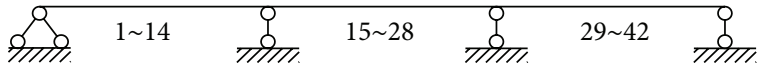

(1) Serial number of component failure mode

FIgURE 12: The component failure modes.

from the model bridge, in which the designated minimum degrees of static indeterminacy are 0,1 , and 2, respectively.

The variation of the system reliabilities for different structural failure modes throughout the service life is displayed in Figure 13, showing that the time-variant system reliabilities with respect to the structural failure modes 2 and 3 are identical. This is because (1) the minimum individual reliability of component failure mode appears on the side span and (2) the structure is symmetrical. Thus, when a component failure mode in a side span occurs, its 
TABLE 5: Key parameters of the structural failure mode.

\begin{tabular}{|c|c|c|c|c|}
\hline Structural failure mode & $\begin{array}{l}\text { Minimum degree of } \\
\text { static indeterminacy }\end{array}$ & $\begin{array}{c}\text { Subset } \\
\text { serial number }\end{array}$ & $\begin{array}{l}\text { Minimum number of } \\
\text { the occurring CFMs }\end{array}$ & $\begin{array}{c}\text { Including } \\
\text { CFMs } \\
\end{array}$ \\
\hline & & 1 & 2 & $1-14$ \\
\hline \multirow[t]{2}{*}{1} & 0 & 2 & 2 & $29-42$ \\
\hline & & 3 & 3 & $1-42$ \\
\hline 2 & 1 & 1 & 2 & $1-42$ \\
\hline 3 & 2 & 1 & 1 & $1-42$ \\
\hline
\end{tabular}

${ }^{*}$ CFMs: component failure modes.

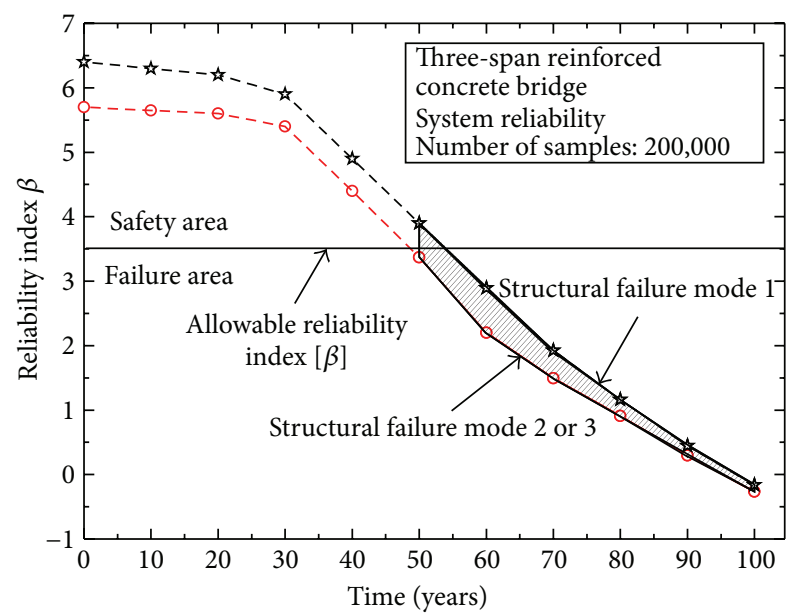

FIGURE 13: Variation of the system reliability.

counterpart in another side span has also appeared. The system reliabilities of different structural failure modes from 0 to 50 years are shown as the dash lines, since they cannot be calculated by using the prescribed number of samples (i.e., $200,000)$. However, we are concerned with the variation of system reliability below the allowable reliability index $[\beta]$ (i.e., in the failure area), which can be evaluated and is shown as solid lines in the figure. The actual system reliability of the overall structure should be between the star-solid line and the circle-solid line, the shadow region of Figure 13, showing that the difference of the system reliabilities among the structural failure modes gradually decreases from 50 to 100 years. In addition, the system reliabilities with respect to all the structural failure modes reduce to negative values at the end of service life. Thus, maintenance interventions are required to improve the structural performance during that life. According to the obtained system reliability profile, the appropriate maintenance application time should be at 50 years when the system reliability is about to decrease to the failure area.

\section{Conclusions}

A finite element- and Monte Carlo simulations-based computational methodology is proposed in this paper to evaluate the time-variant system reliability of deteriorating concrete bridges under environmental attacks. Methods for solving the reduction of concrete section and the variation of structural load effect are investigated for time-variant performance. For system reliability, a novel structural failure mode searching technique is proposed. Accordingly, two programs, CBDAS and SRMCS, are written to perform these analyses from which the time-variant system reliability of deteriorating concrete bridge can be calculated. Finally, two examples are presented to demonstrate the functions of CBDAS, SRMCS, and the combination of the two programs. The following conclusions can be drawn:

(1) The first example shows that the differences of the critical time variants between the edges in a concrete section may be significant due to the various values of the design parameters among the concrete edges. These differences have great influence on deterioration in the reinforcing steel and concrete sections of bridges. Thus, to simulate the actual reduction process of concrete sections, it is necessary to delineate the concrete section by using its edge as the basic unit.

(2) Again from the first example, it is clear that the variations of the performance indicators reflecting the structural serviceability and strength, such as the structural vertical displacement and flexural moment, are significant due to the effect of concrete creep and shrinkage and reduction of sectional areas at the beginning and end of service life and the degree of variation related to the serviceability-performance indicator is more significant than that of strengthperformance indicator. This is because the reduction of reinforcing steel and concrete sections has a great effect on vertical displacement but little effect on flexural moment. Moreover, since essential variables such as the construction process, concrete creep, and shrinkage and the reduction of sectional areas and variations in overall structural performance can be measured collectively by using the finite elementbased approach, the lifetime performance of concrete bridges exposed to aggressive environments can be accurately evaluated.

(3) The time-variant system reliability of concrete bridges with environment attacks can be evaluated accurately using the Monte Carlo simulations-based and the finite element-based approach because (a) determination of the correlation coefficients of the individual component failure modes is not needed in the proposed method; (b) by using the proposed 
finite element-based assessment method, the limit state functions of the individual component failure modes are sufficient to obtain good results; and (c) based on the structural failure mode searching technique, the relationship between the individual component failures and the overall structural failure can be effectively simulated during the lifetime of bridges negatively affected by adverse environmental conditions.

\section{Conflict of Interests}

The authors declare that there is no conflict of interests regarding the publication of this paper.

\section{Acknowledgment}

This research was supported by Zhejiang Provincial Natural Science Foundation of China (no. LQ14E080001).

\section{References}

[1] M. G. Richardson, Fundamentals of Durable Reinforced Concrete, CRC Press, London, UK, 2002.

[2] R. Rackwitz, "Reliability analysis—a review and some perspective," Structural Safety, vol. 23, no. 4, pp. 365-395, 2001.

[3] L. Burgazzi, "About time-variant reliability analysis with reference to passive systems assessment," Reliability Engineering and System Safety, vol. 93, no. 11, pp. 1682-1688, 2008.

[4] Z. Wang and P. Wang, "A new approach for reliability analysis with time-variant performance characteristics," Reliability Engineering \& System Safety, vol. 115, pp. 70-81, 2013.

[5] W. Zhang and H. Yuan, "Corrosion fatigue effects on life estimation of deteriorated bridges under vehicle impacts," Engineering Structures, vol. 71, pp. 128-136, 2014.

[6] J. S. Kong and D. M. Frangopol, "Prediction of reliability and cost profiles of deteriorating bridges under time- and performance-controlled maintenance," Journal of Structural Engineering, vol. 130, no. 12, pp. 1865-1874, 2004.

[7] A. A. Czarnecki and A. S. Nowak, "Time-variant reliability profiles for steel girder bridges," Structural Safety, vol. 30, no. 1, pp. 49-64, 2008.

[8] S. Kim and D. M. Frangopol, "Inspection and monitoring planning for RC structures based on minimization of expected damage detection delay," Probabilistic Engineering Mechanics, vol. 26, no. 2, pp. 308-320, 2011.

[9] F. Biondini and D. M. Frangopol, "Lifetime reliability-based optimization of reinforced concrete cross-sections under corrosion," Structural Safety, vol. 31, no. 6, pp. 483-489, 2009.

[10] A. Titi, F. Biondini, and D. M. Frangopol, Lifetime Resilience of Aging Concrete Bridges under Corrosion, CRC Press, London, UK, 2014.

[11] G. P. Li, Bridge Structure Analysis Composite System, Tongji University Press, Shanghai, China, 1998.

[12] P. Lu, F. Li, and C. Shao, "Analysis of a T-frame bridge," Mathematical Problems in Engineering, vol. 2012, Article ID 640854, 14 pages, 2012.

[13] H. Tian, Research on Structure Performance Evolution of Concrete Bridges in Given Service Life, Department of Bridge Engineering, Tongji University, Shanghai, China, 2009.
[14] Q. Gu, "Performance and risk assessment of soil-structure interaction systems based on finite element reliability methods," Mathematical Problems in Engineering, vol. 2014, Article ID 704804, 16 pages, 2014.

[15] S.-I. Yang, D. M. Frangopol, Y. Kawakami, and L. C. Neves, "The use of lifetime functions in the optimization of interventions on existing bridges considering maintenance and failure costs," Reliability Engineering \& System Safety, vol. 91, no. 6, pp. 698705, 2006.

[16] N. M. Okasha and D. M. Frangopol, "Lifetime-oriented multiobjective optimization of structural maintenance considering system reliability, redundancy and life-cycle cost using GA," Structural Safety, vol. 31, no. 6, pp. 460-474, 2009.

[17] A. S. Nowak and K. R. Collins, Reliability of Structures, McGraw-Hill, New York, NY, USA, 2000.

[18] E. Bastidas-Arteaga, P. Bressolette, A. Chateauneuf, and M. Sánchez-Silva, "Probabilistic lifetime assessment of RC structures under coupled corrosion-fatigue deterioration processes," Structural Safety, vol. 31, no. 1, pp. 84-96, 2009.

[19] S. Y. Kim and D. M. Frangopol, "Optimal planning of structural performance monitoring based on reliability importance assessment," Probabilistic Engineering Mechanics, vol. 25, no. 1, pp. 86-98, 2010.

[20] H. Tian, X.-P. Jin, and A.-R. Chen, "Probabilistic-based effect analysis of different maintenance actions on reinforced concrete bridges," Journal of Zhejiang University Engineering Science, vol. 46, no. 6, pp. 1097-1121, 2012.

[21] C. A. Cornell, "Bounds on the reliability of structural systems.93(ST1)," Journal of Structural Division, vol. 93, no. 1, pp. 171-200, 1967.

[22] A. Der Kiureghian, H.-Z. Lin, and S.-J. Hwang, "Second-order reliability approximations," Journal of Engineering Mechanics, vol. 113, no. 8, pp. 1208-1225, 1987.

[23] H.-C. Liu, L. Liu, and N. Liu, "Risk evaluation approaches in failure mode and effects analysis: a literature review," Expert Systems with Applications, vol. 40, no. 2, pp. 828-838, 2013.

[24] R. Kanapady and R. Adib, "Application of modeling and simulation for high risk failure modes," in Proceedings of the Annual Reliability and Maintainability Symposium, pp. 1-6, IEEE, Reno, Nev, USA, January 2012.

[25] P. Wei, Z. Lu, and B. Ren, "Reliability analysis of structural system with multiple failure modes and mixed uncertain input variables," Proceedings of the Institution of Mechanical Engineers Part C: Journal of Mechanical Engineering Science, vol. 227, no. 7, pp. 1441-1453, 2013.

[26] Code for Design Reinforced Concrete and Prestressed Concrete Bridges and Culverts, China Communications Press, Beijing, China, 2004. 


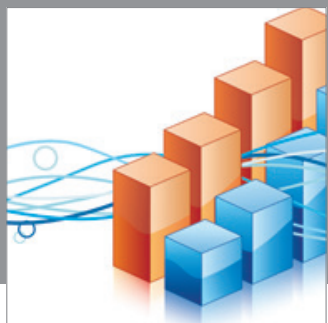

Advances in

Operations Research

mansans

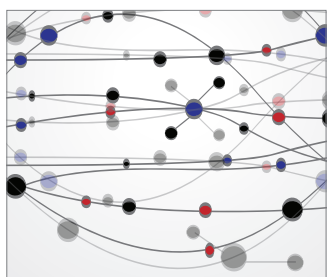

The Scientific World Journal
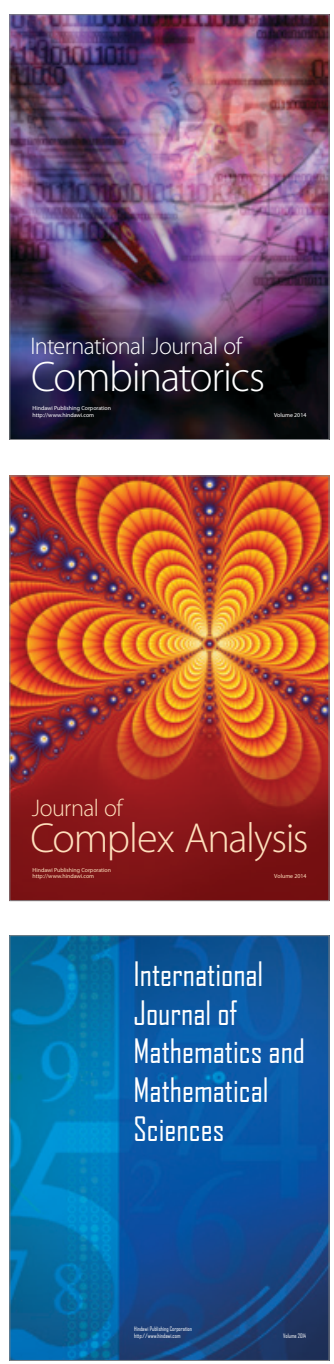
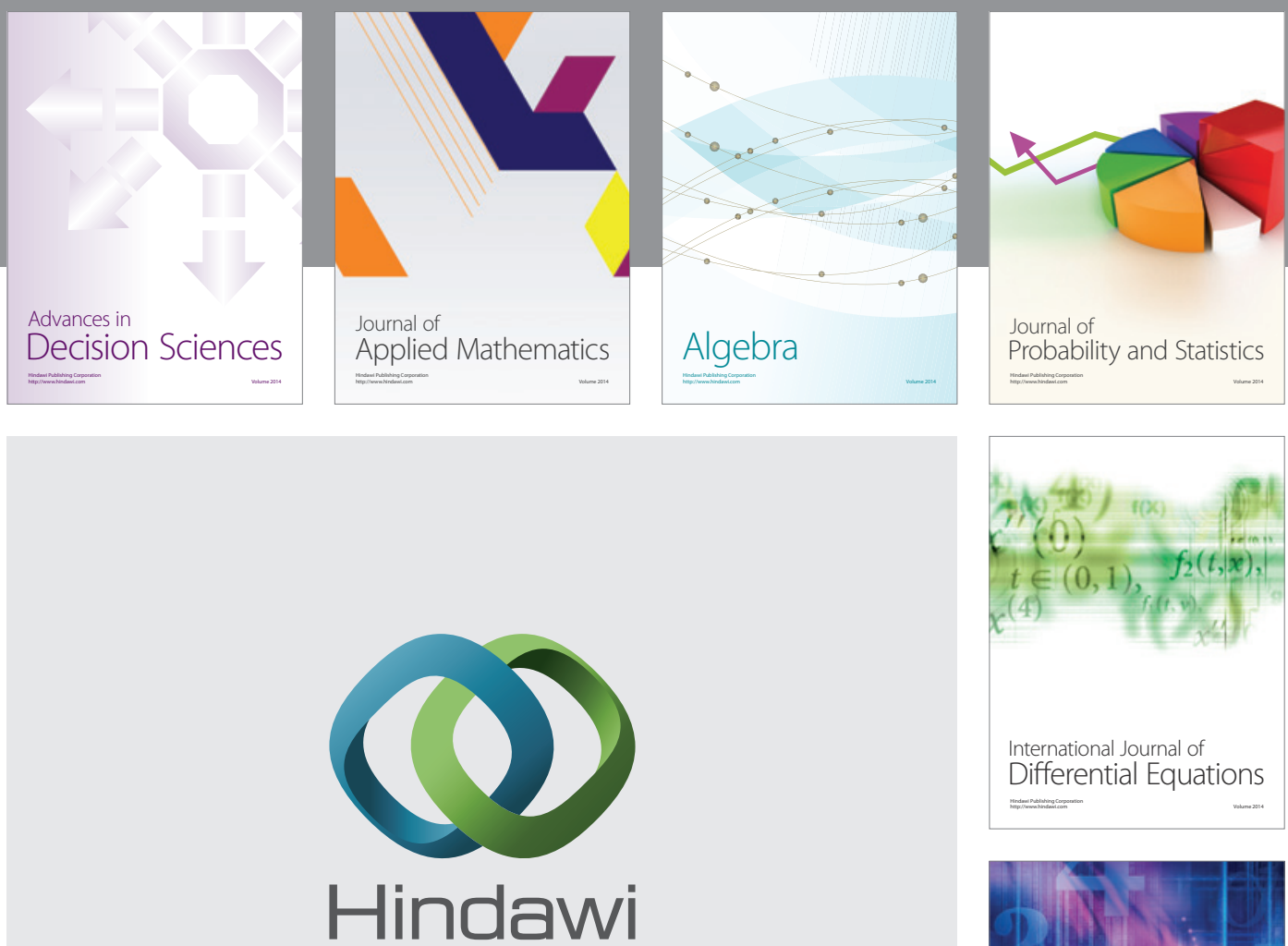

Submit your manuscripts at http://www.hindawi.com
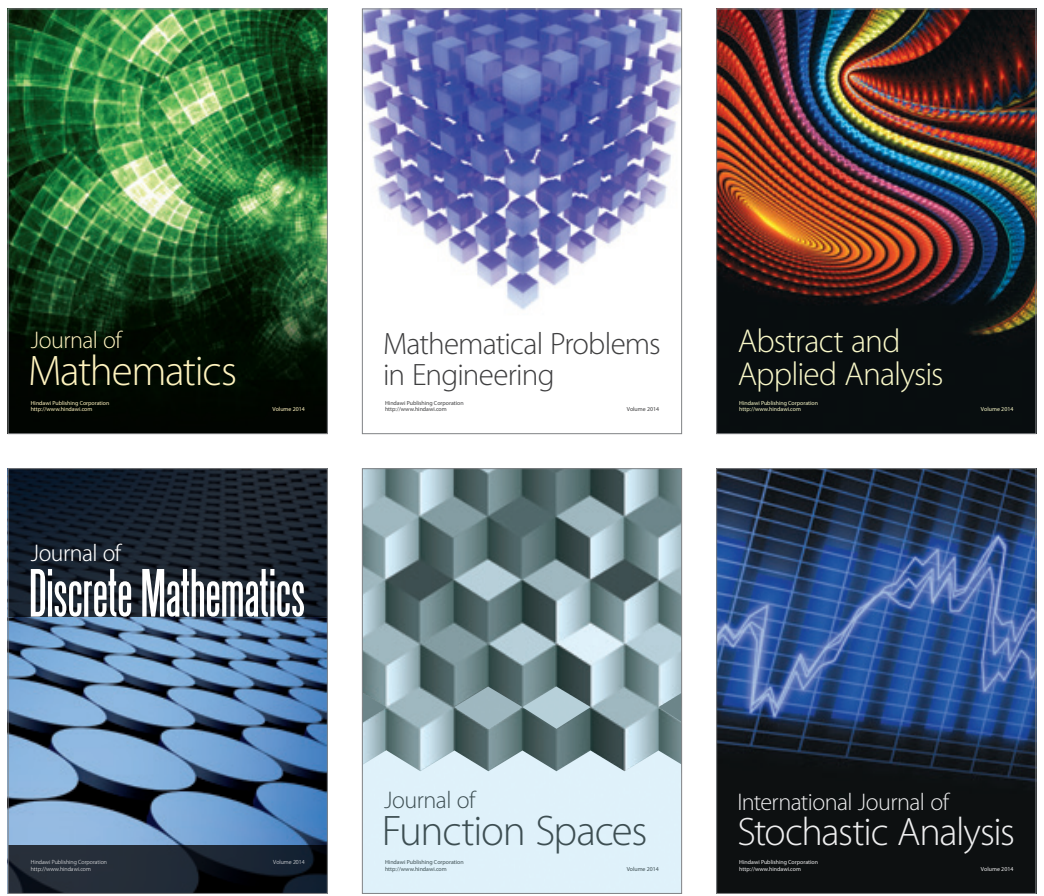

Journal of

Function Spaces

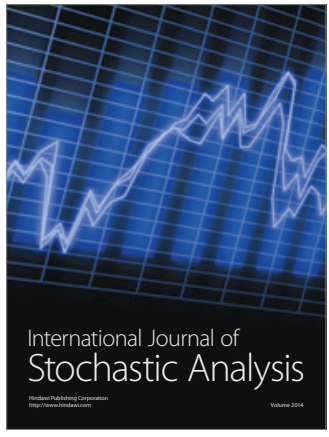

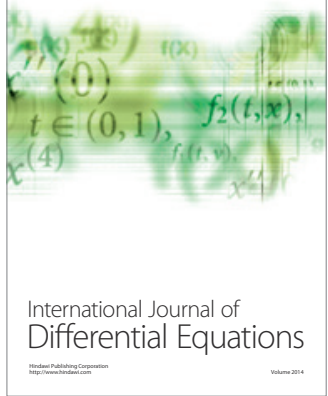
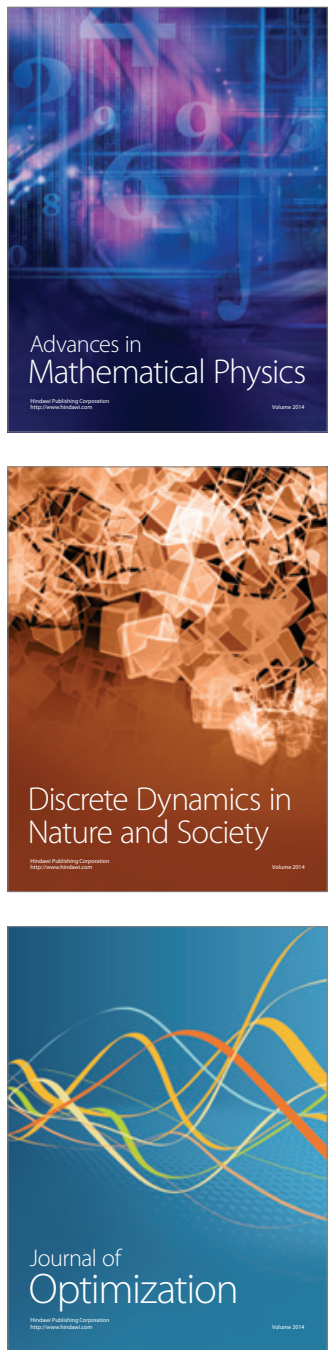